\title{
生态化学计量学:复杂生命系统奥秘的探索
}

\author{
曾德慧 ${ }^{1}$ 陈广生 ${ }^{1,2}$ \\ （1 中国科学院沈阳应用生态研究所大青沟沙地生态实验站, 沈阳 110016) \\ (2 奥本大学林业与野生动植物系, 奥本 AL 36849-5418, 美国)
}

\begin{abstract}
摘 要 20 世纪以来, 生物科学的发展异军突起, 成为发展最快的学科, 不仅学科分类逐渐细化, 而且研究领域也 逐渐深入, 然而, 这种分化和深入也可能会掩盖生物的一些最普遍特征。地球上的生物是否具有统一的、更本质的 特征? 能否把不同生物学领域和不同层次的知识联系起来? 随着对这些问题的不断探索,一门新兴的学科一一生 态化学计量学, 在最近 20 年悄然兴起。生态化学计量学结合了生物学、化学和物理学等基本原理, 是研究生物系 统能量平衡和多重化学元素(主要是 C、N、P) 平衡的科学。这一研究领域使得生物学科不同层次 (分子、细胞、有机 体、种群、生态系统和全球尺度)的研究理论能够有机地统一起来。目前, 生态化学计量学已经广泛应用于种群动 态、生物体营养动态、微生物营养、寄主-病原关系、生物共生关系、消费者驱动的养分循环、限制性元素的判断、生态 系统比较分析和森林演替与衰退及全球 C、N、P 生物地球化学循环等研究中, 并取得了许多研究成果。该文概述了 生态化学计量的概念、历史起源和基本理论, 重点介绍了生态化学计量学理论在消费者驱动的养分循环、限制性养 分元素判别以及全球 C、N、P 循环等方面的应用进展, 并对生态化学计量学未来的研究方向进行了展望, 期望引起 国内同行的重视并有助于推动我国在此领域开展相关研究。
\end{abstract}

关键词 生态化学计量 $\mathrm{C}: \mathrm{N}: \mathrm{P}$ 化学计量比 Redfield 比值 动态平衡理论 生长速率理论

\section{ECOLOGICAL STOICHIOMETRY: A SCIENCE TO EXPLORE THE COMPLEXITY OF LIVING SYSTEMS}

\author{
ZENG De-Hui ${ }^{1}$ and CHEN Guang-Sheng ${ }^{1,2}$ \\ (1 Daqinggou Ecological Station, Institute of Applied Ecology, Chinese Academy of Sciences, Shenyang 110016, China) \\ (2 School of Forestry and Wildlife Sciences, Auburn University, Auburn, AL 36849-5418, USA)
}

\begin{abstract}
The biological sciences developed very fast during the 20th century and have become increasingly sophisticated and predictive. Along with this trend, areas of research also have become increasingly specialized and fragmented. However, this fragmentation and specialization risks overlooking the most inherent biological characteristics of living organisms. One can ask if the living organisms on the earth have unified and essential characteristics that can connect the disparate disciplines and levels of biological study from molecular structure of genes to ecosystem dynamics. By exploring this question, a new science, ecological stoichiometry, has been developed over the past two decades. Ecological stoichiometry is a study of the mass balance of multiple chemical elements in living systems; it analyzes the constraints and consequences of these mass balances during ecological interactions. All biological entities on the earth have a specific elemental composition and specific elemental requirements, which influence their interactions with other organisms and their abiotic environment in predictable ways. Ecological stoichiometry has been incorporated successfully into many levels of biology from molecular, cellular, organismal and population to ecosystem and globe. At present, the principles of ecological stoichiometry have been broadly applied to research on population dynamics, trophic dynamics, microbial nutrition, host-pathogen interactions, symbiosis, comparative ecosystem analysis, and consumer-driven nutrient cycling. This paper reviews the concepts, research history, principles, and applications of ecological stoichiometry and points out future research hotspots in this dynamic field of study with an aim to promote this discipline of research in China.
\end{abstract}

Key words Ecological stoichiometry, $\mathrm{C}: \mathrm{N}: \mathrm{P}$ stoichiometric ratio, Redfield ratio, Homeostasis, Growth rate hypothesis 
20 世纪以来, 生物科学已经逐渐成熟, 可预测 性逐渐增强, 随着这种成熟的逐渐专业化, 生物学研 究方向的窄化现象不仅发生在生物组织的不同水平 上(如, 分子、个体、种群和生态系统), 而且发生在特 定的模式生物范围内(如, 线虫 (Anguina) 、水蚤 (Daphnia)、果蝇 (Drosophila) 及拟南芥 (Arabidop$s i s)$ ), 或者特定的生境中 (如, 湖泊、森林、海洋和草 地) (Elser et al., 2000b)。这种生物学知识的逐渐 分化, 使得不同领域的联系变得更加困难, 从而阻碍 了把整个生物界作为一个功能整体来进行研究 (Allen \& Hoekstra, 1992; Vogel, 1998)。目前, 生物 学家面临着发展综合性理论去研究生物系统的挑 战, 这种理论必须把我们已深刻了解的个体水平生 物有机体联系起来, 而且必须强调各种生物群体和 生态系统的一致性特征 (Michaels, 2003)。

地球上的所有生物是否具有统一的特征呢? 是 否可能在现代生物科学框架下提出一种理论去连接 各种不同的组织水平(从基因的分子结构到生态系 统)? 要整合各种组织水平、有机体类型和各种生境 的生物学知识确实是一个很大挑战。一个结合热力 学第一定律、生物进化的自然选择原理和分子生物 学中心法则的理论应运而生 (Michaels, 2003), 这一 理论就是“生态化学计量学”(Ecological stoichiometry) 或称为“化学计量生态学”( Stoichiometric ecology)。

生态化学计量学理论对于生物学研究具有重要 意义, 2004 年第 85 卷第 5 期 Ecology 杂志刊登了“Ecological stoichiometry”特别专栏, 介绍了欧美多个国 家有关研究小组的最新研究进展。由此可见该杂志 编辑部希望生态化学计量学这一新兴学科能够引起 科学家们更广泛的关注。相对国际上对生态化学计 量学研究十分活跃而言, 生态化学计量学在中国目 前尚没有受到广泛关注 (张明霞, 2003), 鉴于此, 本 文介绍了生态化学计量学的概念、研究历史、理论及 应用情况, 期望对促进国内相关研究工作的开展起 到一个抛砖引玉的作用。

\section{1 生态化学计量学的概念}

Stoichiometry 是一个化学术语, 它起源于希腊语 的两个词汇“ stoicheion”和“ metron”, 中文含义分别为 “元素”和“测量”, 因此, stoichiometry 意为“测量元素 的科学”, 在化学中称为化学计量学。化学计量学是 指研究参加化学反应的物质量或者是化学反应产物 质量的科学, 它最早由 Richter 在 1792 年提出 (Sherman \& Kuselman, 1999), 主要处理物质转换和化学
反应中物质的质量间关系问题, 重点强调物质的化 学成分与结构关系, 如化学反应的质量、原子量、分 子量和百分比计算。作为化学反应方程中的系数, 摩尔比 (Molar ratio) 在解决化学计量问题中占有中 心位置。化学计量学主要原理包括: 1) 定比定律 (Law of constant composition, 也称作 Law of definite proportions), 其内涵为, 每种化合物都有完全确定的 组成; 2) 倍比定理 (Law of multiple proportions), 其内 涵为, 不同的元素化合时,这些元素的原子按简单整 数比结合成化合物; 3 ) 质量守恒原理 (Mass conservation principle), 其内涵为, 参加化学反应物质的原子 种类和数量与化学反应产物的原子种类和数量保持 不变。

生物世界都是由元素组成的, 因此, 生态学中也 有化学计量规律, 就像实验室的化学反应一样。生 态交互作用无疑要涉及化学元素的重组, 因此, 有机 体交互作用过程中化学元素的组合也要遵循质量守 恒定律。从化学计量学角度来看, 整个有机体就如 一个单一的复杂分子 (Sterner \& Elser, 2002), 分子内 部和分子之间不断进行着化学重组。因此, 从这一 角度来说, 当研究者想要了解某种生物的生物学特 性时, 无疑应首先确定该生物的化学组成特征。在 这种意义下, 每个有机体或生态系统能够被还原为 一个简单的化学计量组成。尽管这种简化并没有实 际作用, 但可以引发我们产生一些思考: 各种有机体 是否存在一个固定的化学计量比值? 不同有机体的 化学元素组成是否相互影响? 如果有机体所需要的 其中一个组成元素不足, 将会出现什么情况? 而这 种有机体会对生态系统产生什么影响 ( Michaels, 2003 )?

在生态学背景下,生态化学计量学结合了生态 学和化学计量学的基本原理, 是研究生物系统能量 平衡和多重化学元素 (通常是 $C 、 N 、 P 、 O 、 S$ ) 平衡的 科学, 它是分析多重化学元素的质量平衡对生态交 互作用影响的一种理论 (Elser et al., 1996; Hessen, 1997)。生态化学计量通常指的是有机体的元素组 成, 主要强调的是活有机体的主要组成元素(特别是 C、N、P)的关系。

Reiners 是最早把化学计量学作为生态系统功 能的一个补充模型的研究者之一, 他认为化学计量 学补充并延伸了生态能量学 (Ecological energetics) (Reiners, 1986)。生态能量学自从 Lindeman( 1942) 提出后, 就一直是生态学中生物物理分析的主要模 式。化学计量学思想在生态学中应用的关键就是实 
现生物实体(如, 分子、细胞器、细胞和有机体等)能 够根据它们的元素组成而加以明显区分, 因为这些 元素的组成差异是与重要生态功能相联系的 (Elser et al . 1996), 因此,生物体与生物体之间、生物体与 非生物环境之间的相互作用方式不仅会受到相关生 物体对元素需求的强烈影响, 也会受到周围环境化 学元素平衡状况的影响 (Elser \& Urabe，1999)。

生态化学计量学理论认为有机体都是由元素构 成的,这些元素的比值不仅决定了有机体的关键特 征, 也决定了有机体对资源数量和种类的需求 （Schimel，2003）。实际上, 有机体的这种特征包含 了 3 层涵义: 第一, 因为元素是有机体的最基本组 成, 所以生物进化将明显影响有机体的元素比值, 因 此, 生态化学计量学理论可以直接与生物进化相联 系; 第二,环境对有机体元素比值的影响很大, 不同 的地质、气候和生物等因素都会影响它; 第三, 有机 体通过消耗和释放不同于环境元素比值的元素, 从 而对其周围环境元素的比值产生影响。因此, 环境 的元素化学计量比值和有机体的化学计量比值之间 就形成了复杂的反馈关系, 一旦两者的化学计量比 值不相匹配, 就会引发有机体种群行为和进化的改 变( Schimel, 2003), 也会影响生物的生长发育过程 和形态的改变 (Méndez \& Karlsson, 2005)。可以认 为, 有机体的生态化学计量学理论连接了生物系统 的 3 个尺度: 分子水平(进化机理)、有机体水平和大 尺度的生态系统过程。

生态化学计量学在研究元素动态和元素间关系 的基础上建立一个共识, 即有机体是由元素组成, 而 这些元素进一步组成了各种各样的有机化合物 (还 有一些无机骨架和金属螯合物), 每种主要的化合物 都具有自己独特的化学计量值。比如, 碳水化合物 含 $\mathrm{C}$ 和 $\mathrm{N}$ 丰富而含 $\mathrm{P}$ 少, 核苷含 $\mathrm{N}$ 和 $\mathrm{P}$ 很高。在有 机体水平, 生物的化学组成可以反映进化的结果, 这 些进化的结果包括影响生物生长速率、健康状况、新 陈代谢、结构和生态演替的某些方面 ( Michaels, 2003)。

活有机体的元素组成相对比较稳定, 这种稳定 性是通过它们积极调控细胞组成成分或体内环境来 保持的。植物对其生物化学环境的选择具有更大弹 性, 因此, 它们的元素组成也比动物和微生物变化更 大。但是, 所有有机体的化学计量值的差异比我们 通常想象的要大, 而且物种之间的变化可能与分类 群间的变化一样大 (Michaels, 2003)。总体上, 植物 无机养分的比值变化范围很大, 而以植物或其它动
物为食的动物养分元素组成变化范围较小。

为什么要在生态学中聚焦于化学元素呢? 首 先, 元素容易在不同生物组织水平间移动, 因此, 能 够计算元素的组成和估测进入或流出各种生物实体 化学元素的通量; 其次, 元素是不变的, 因此可以利 用质量守恒原理去研究元素在各组织水平间的流动 量; 第三, 有机体都是化学实体, 都是由化学反应产 生、维持和增殖的, 尽管这些反应都是以很复杂和耦 合的反应网形式进行的 (Sterner \& Elser, 2002)。

\section{2 生态化学计量学研究历史}

化学计量学理论在生态学上的应用可以追溯到 1862 年李比希提出的最小量定律 (Liebig' s law of the minimum), 该理论认为在组成生物体的资源中, 相对 需求而言供应量最少的资源将成为限制该生物生长 的主要因素, 即有机体受到与需求量相比供应量最 小资源的限制。该理论阐明的一个重要思想就是生 物体的元素组成平衡对生物体生长是非常重要的。 李比希认为化学在动物和植物生理学研究中具有重 要地位, 他的理论已经促成了一系列对有机体适应 贫痊环境的生态学和生理学研究, 其中许多研究表 明, 限制性元素含量不同, 有机体元素组成会产生相 应变化。此后, Lotka( 1925)在他的《物理生物学的基 础》( Elements of Physical Biology) 一书中, 提出了捕食 者-猎物相互作用模型, 定量阐述了生物之间的相互 作用关系。Lotka 是第一个考虑物理-化学系统热力 学定律与生物世界相联系的人, 他的思想在生态学 得到广泛应用并发展出了许多生态学基础理论: 最 佳取食理论 (Optimal foraging)（Belovsky，1978)、资源 比理论 (Resource-ratio theory)(Tilman, 1982)、海洋生 物地球化学循环中的 Redfield 比值 (Redfield, 1958) 和养分利用效率 (Vitousek, 1982) 等。因此, 也有人 认为 Lotka 的理论是生态化学计量学理论的最早起 源 (Elser et al ., 2000b)。尽管 Redfield 认识到有机 体的化学计量组成总是不断变化的, 但是, 他对海洋 中的无机养分比值和有机体的元素组成之间存在显 著的一致性感到很惊奇, 通过试验他确定了当养分 不受到限制时浮游植物的元素比值关系为 $\mathrm{C}: \mathrm{N}: \mathrm{P}$ $=106: 16: 1$, 这一比值关系被称为 Redfield 比值 ( Redfield ratio) ( Redfield, 1958; Redfield et al., 1963)。尽管后来证明 $\mathrm{C}: \mathrm{N}: \mathrm{P}$ 比值是不断变化的, 但是, 海洋浮游植物中 $\mathrm{C}: \mathrm{N}: \mathrm{P}$ 比值明显恒定性假设 的提出, 促成了海洋生物地球化学研究的极大发展。 Tilman（1982) 在 Lotka-Volterra 理论的基础上提出了 
资源比理论, 这个理论认为单个物种的生长速率是 限制性资源可利用量的函数, 而资源的可利用量又 是环境的资源供应速率和物种消耗速率的函数; 资 源在物种生长速率和物种间的竞争中起着关键的作 用, 因此, 可以利用资源的流动和含量来预测物种的 多度格局、物种共存和生物多样性。Vitousek (1982) 提出了养分利用效率的概念, 他把养分利用效率定 义为, “植物损失单位养分造成的有机质从植物体损 失的量或永久性储存单位养分而获得永久性储存在 植物体内的有机质数量。”该概念可以简单地理解为 单位养分的生产力, 实际上它表述了碳 (生物量)与 养分的比值关系。养分利用效率提出后逐渐成为生 态系统生态学的一个中心概念。

Reiners（1986）在其文章“C Complementary models for ecosystems" 中首次明确地把化学计量学理论作为 生态系统研究的一个补充理论, 从而使生态学与化 学计量学有机结合起来。在该文中, Reiners 阐明了 化学计量学理论在生态学中的应用, 并且提出了结 合化学计量学理论的生态学研究理论模型。尽管作 者并未直接使用生态化学计量学一词表示这一理 论, 但实际上该理论模型已经很清晰地阐明了生态 化学计量学的基本理论框架。Reiners 的生态化学 计量学思想提出后, 许多研究者, 特别是海洋生物学 家开始注意这一新的理论, 大量的研究开始于 20 世 纪 90 年代, 这些研究验证并补充了生态化学计量学 理论。以 Sterner 和 Elser (2002) 的著作《生态化学计 量学: 从分子到生物圈的元素生物学》一书的出版为 标志,生态化学计量学理论基本得到完善,这一理论 也逐渐被许多生物学家认同（Harris，2003; Schindler, 2003)。著名生态学家 Vitousek 在该书前 言中坦言, 该书的出版是生态学研究史上的重要里 程碑。Michaels (2003) 认为生态化学计量学理论将 不同尺度、不同生物群系和不同研究领域的生物学 研究有机联系起来了。

\section{3 生态化学计量学的基本理论}

作为一门新学科,生态化学计量学的正式提出 只有不到 20 年的历史。但是, 由于化学计量学在生 态学上的应用已有很长的历史, 生态化学计量学理 论的发展、完善及应用过程十分迅速。

1986 年, Reiners 提出了结合化学计量学与生态 学的生态系统研究补充模型, 该模型列出了生态化 学计量学的基本理论脉络。由于发表该文章时, 受 生物的化学计量组成较稳定思想的影响, Reiners 在
该理论模型中一些公理并非完全准确, 因此, Sterner 和 Elser (2002) 对该理论模型进行了修正, 以 9 个公 理和 6 个定理形式对生态化学计量学理论进行了区 分(图 1)。这一新修正的模型表明了层次较低的化 学计量过程能够创建 (Create) 较高层次的生态学过 程和格局。

此外,生态化学计量学还发展了两个重要的具 体理论, 即动态平衡原理和生长速率理论。有机体 化学元素组成的动态平衡原理是生态化学计量学理 论成立的理论基础。正常的生物体的养分元素组成 基本比较稳定, 即使外界环境不断变化下, 其组成也 不会发生很大变化; 但是, 如果受到某种极端环境因 子的影响, 造成元素组成产生巨大变化, 超出了其能 够忍受的极限, 这种有机体就可能无法生存, 这就是 生态学上的“Shelford 耐受定律”在有机体元素组成 上的一个反映。因此, 有机体要生存必需具备一个 负反馈机制, 即, 有机体内部环境 (比如, 消费者的元 素计量比值)和外部环境 (比如, 食物的元素计量比) 保持一种相对稳定的格局。这种有机体与其环境保 持一种相对稳定的平衡状态的现象就被称为“动态 平衡” (Homeostasis)。Kooijman( 1995) 以化学计量学 的观点定义动态平衡为“使大多数有机体保持身体 化学元素组成相对稳定的能力, 尽管环境(包括有机 体的食物)的化学元素组成发生变化”。生物学中的 动态平衡就要使有机体内部的环境 (如消费者的元 素计量比等)不随外部环境(如资源的元素计量比 等)的变化而剧烈变化, 从而使整个有机体基本保持 稳定, 因此, 动态平衡被认为是生命的本质特征。有 机体能够控制它们自身的许多特性, 包括养分平衡、 $\mathrm{pH}$ 值稳定等, 从而在一定范围内维持其稳定性。在 生态化学计量学中, 有机体元素的动态平衡是指有 机体中元素组成与它们周围环境(包括它们利用的 资源) 养分元素供应保持相对稳定的一种状态 (Sterner \& Elser, 2002)。动态平衡使生物的化学物 质组成产生不同程度的变化以及保持一定程度的稳 定, 因此, 它是生态化学计量学存在的理论基础。

“生长速率理论”( Growth rate hypothesis, GRH) 是有机体生态化学计量控制的基本途径, 这个理论 提供了生态化学计量控制生命进化、细胞生物学特 性、种群动态和生态系统功能机制的基本框架 (Reiners, 1986; Elser et al., 2000b; Vanni et al., 2002 )。这种与 $\mathrm{C}: \mathrm{N}: \mathrm{P}$ 化学计量比、RNA 分配和有 机体生活史相关的机制就被称为生长速率理论 (Elser et al., 1996, 2000a)。GRH 认为生物体必须 


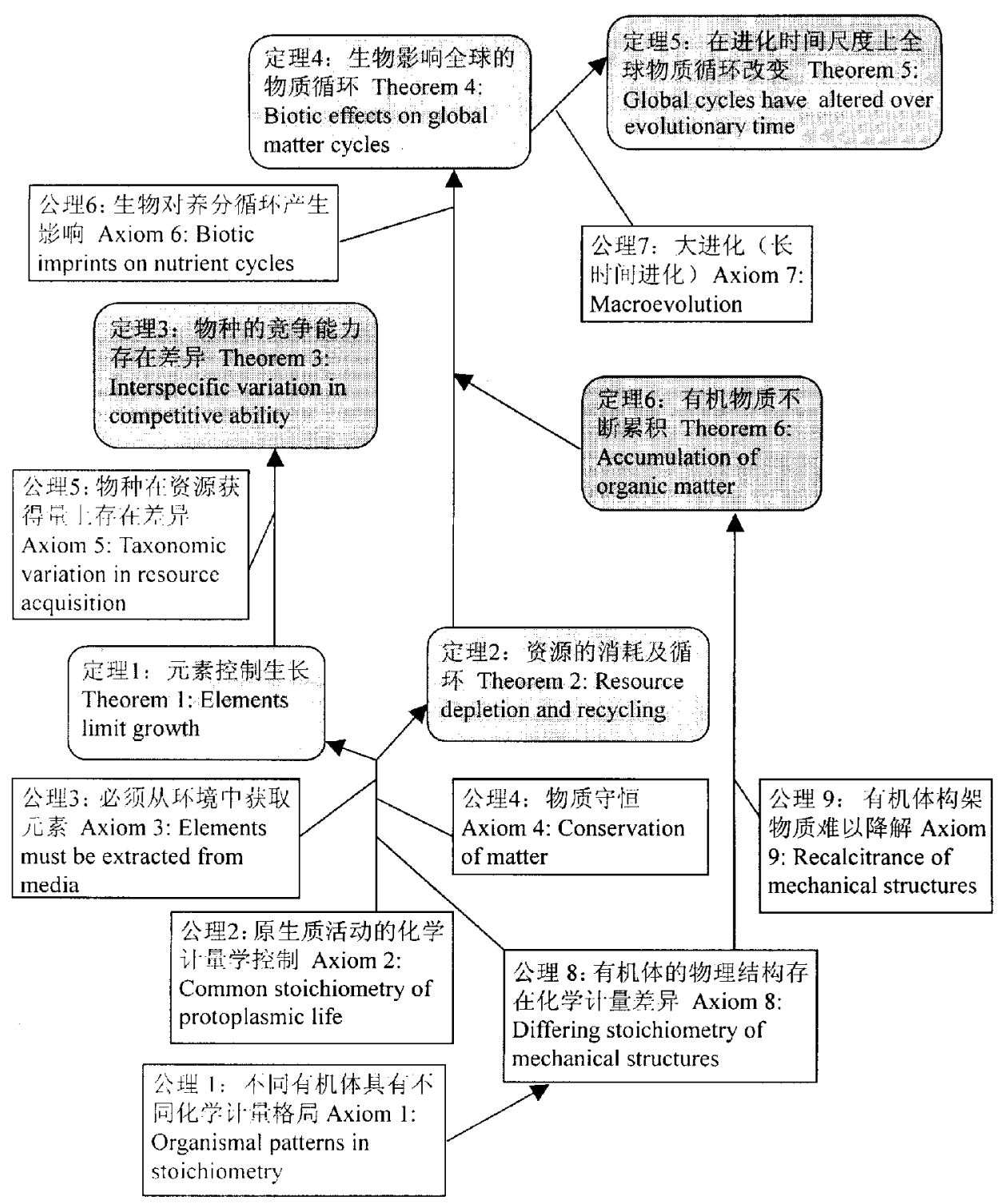

图 1 生态化学计量学的基本理论结构 (Sterner \& Elser, 2002)

Fig. 1 Basic theory constituents of ecological stoichiometry (Sterner \& Elser, 2002)

改变它们的 $\mathrm{C}: \mathrm{N}: \mathrm{P}$ 比值以适应生长速率的改变。 对许多异养生物来说，高的生长速率不仅对应高的 $\mathrm{N}: \mathrm{C}$ 和 $\mathrm{P}: \mathrm{C}$ 比, 而且对应低的 $\mathrm{N}: \mathrm{P}$ 比值 (Elser $e t$ al., 2003; Makino et al., 2003)。GRH 最初起源于 对最适条件下, 不同物种生物量 $\mathrm{C}: \mathrm{P} 、 \mathrm{~N}: \mathrm{P}$ 和最大生 长速率的比较研究 (Elser et al., 1996; Main et al., 1997), 这种理论也适用于同种生物的生物量 $\mathrm{C}: \mathrm{N}$ 和 $\mathrm{N}: \mathrm{P}$ 比变化的研究 (Hessen, 1990), 因为生长速率 和 RNA 含量会随年龄增加而降低 (Gorokhova \& Kyle, 2002)。

生长速率理论把生物组织的不同层次 (分子、个 体、种群和生态系统)有机联系起来了。生长速率理
论认为, 单个有机体 $\mathrm{P}$ 的生物地球化学过程与生长 和繁殖紧密相关 (它是该种群动态的一个主要决定 者)(Elser et al., 1996)。具体来说, 有机体 $\mathrm{C}: \mathrm{N}: \mathrm{P}$ 比的变化主要是由生物体 $\mathrm{P}$ 含量的变化决定 (Vanni et al. , 2002)。生物体 $\mathrm{P}$ 的变化至少部分受不同生 长或发育速率的有机体 $\mathrm{rRNA}$ 中 $\mathrm{P}$ 含量变化的影响 （Elser et al., 1996）。有机体必须调整它们的 $\mathrm{C}: \mathrm{N}: \mathrm{P}$ 化学计量比来适应生长速率的改变, 因此, 生长快速 的有机体通常具有较低的 $\mathrm{C}: \mathrm{P}$ 和 $\mathrm{N}: \mathrm{P}$ 比值 (Elser et $a l$, 2003; Makino et al., 2003)。这种较低的 C: $\mathrm{P}$ 和 $\mathrm{N}: \mathrm{P}$ 比值反映了分配到 $\mathrm{rRNA}$ 中 $\mathrm{P}$ 的增加, 因为核 糖体需要快速地合成蛋白质以支持快速生长。这种 
直接或间接地造成生活史特性产生变化的演化过程 会对有机体的元素组成产生影响 (Elser et al., $2000 \mathrm{~b}$ ), 因此, 生长速率理论将细胞的物质分配与生 物体的功能及其动态特征联系起来了。GRH 假设 已经在许多物种上得到验证, 比如, 异养细菌大肠杆 菌( Escherichia coli)( Makino et al., 2003), 以及浮游 动物和陆地上的昆虫等( Elser et al., 2003)。但是, 这些验证都是基于单个物种研究基础上获得的。 Makino 和 Cotner (2004) 通过多种细菌混合的实验表 明, 高 $\mathrm{C}: \mathrm{P}$ 比 ( $\geqslant 373$ ) 供应下的细菌群落, 其 RNA 含 量增加, 生物量中 $\mathrm{P}$ 含量的增加与细菌生长速率成 正比, 正如 GRH 预测, 高的生长速率造成低的生物 量 $\mathrm{C}: \mathrm{P}$ 和 $\mathrm{N}: \mathrm{P}$ 比值; 而当以低的 $\mathrm{C}: \mathrm{P}$ 比 (93:1) 供应 时, 虽然细菌 RNA 含量仍然增加, 但是, 生物量 $\mathrm{C}: \mathrm{P}$ 和 $\mathrm{N}: \mathrm{P}$ 也随着生长速率的增加而增加, 这种情况却 不符合 GRH 理论的预测结果。因此, 他认为只有在 $\mathrm{P}$ 限制的情况下 ( $\mathrm{C}: \mathrm{P}$ 比很高), 由 $\mathrm{GRH}$ 预测的生态 化学计量比值与生长速率的关系在生物群落和个体 水平上都成立; 而在不受 $\mathrm{P}$ 限制的情况下, 细菌群落 生长对养分供应的反应不符合 GRH 预测的结果, 这 可能是由于细菌群落的生长对养分计量比值的反应 比单个有机体更加复杂的原因。

\section{4 生态化学计量学的应用}

自 Reiners ( 1986) 提出生态化学计量学思想以 来, 许多科学家对此开展了研究, 生态化学计量学的 应用领域不断拓展, 目前生态化学计量学理论已经 应用于包括营养动态 (Sterner \& Hessen, 1994; Andersen, 1997)、微生物营养( Tezuka 1989; Chrzanowski et al., 1996)、寄主-病原关系 (Smith, 1993a)、共生 (Smith, 1993b)、比较生态系统分析 (Comparative ecosystem analysis)( Downing, 1997; Jaenike \& Markow, 2003 )、消费者驱动的养分循环 (Sterner, 1990; Urabe et al. , 1995; Elser \& Urabe, 1999)、生物的养分限制 (Koerselman \& Meuleman, 1996; Aerts \& Chapin, 2000; Tessier \& Raynal, 2003)、碳循环 (Lerman et $a l$, 2000; Hessen et al., 2004)、种群动态 (Urabe et al., 2002; Andersen et al., 2004)、森林演替与衰退 (Wardle et al., 2004) 和生态系统养分供应与需求的 平衡 (Vitousek, 2003; Schade et al., 2005) 等研究, 生态化学计量学理论不断得到丰富和验证。本文只 重点介绍生态化学计量学理论在消费者驱动的养分 循环、限制性养分元素判别以及全球 C、N、P 循环等 方面的应用进展。

\section{1 消费者驱动的养分循环}

通过把生态化学计量学应用到消费者驱动的养 分循环过程, 生态学家逐渐认识到消费在控制诸如 养分循环等生态系统过程中的作用。最近 20 年来, 在海洋和陆地生态系统的养分循环和营养关系的理 解上取得了很大进步。

有机体与有机体之间、有机体与非生物环境之 间的相互作用方式受到相关的生物体对元素需求的 强烈影响, 同时也受到周围环境的化学元素平衡的

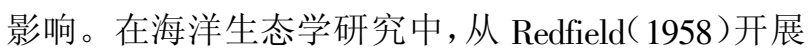
海洋生物研究以来, 对生物间相互作用的研究取得 了很大进展。这些研究表明在全球海洋尺度甚至生 物圈尺度上, 海洋浮游植物的特征性元素比值在全 球主要元素 ( O、C、N、P 等) 的生物地球化学循环中 留下了它们的印痕。但是, 直到最近海洋生态学家 才认识到化学计量学过程也发生在食物网的其它食 物链上(Elser \& Urabe, 1999)。

消费者和它们食物的化学组成的差异能够影响 消费者的取食行为 (White, 1993)、消费者种群稳定 性( White, 1993; Sterner \& Hessen, 1994; Andersen, 1997) 和群落组织结构 (White, 1993; Andersen, 1997)。自养生物的养分含量变化很大, 因此, 其 $\mathrm{C}: \mathrm{N}: \mathrm{P}$ 比值变化也很大。相比之下, 消费者的养分 含量变化范围更小, 通常维持一个比较严格的 $\mathrm{C}: \mathrm{N}$ : $\mathrm{P}$ 比值。因此, 当消费者和它们的食物之间的化学 计量比值出现不平衡时, 消费者的生长和活动将会 受到影响 (Logan et al ., 2004; Hessen et al., 2004)。 化学计量平衡也会对营养动态 ( Urabe \& Sterner 1996; Sterner et al., 1998) 和食物网中的生物地球 化学循环 (Andersen, 1997; Sterner et al., 1992; Urabe et al., 1995; Elser \& Urabe, 1999)产生影响。 许多研究表明 ( Stelzer \& Lamberti, 2002; Ward \& Cummins 1979; Elser et al., 2003), 低的食物质量 (高 $\mathrm{C}: \mathrm{N}$ 或 $\mathrm{C}: \mathrm{P}$ 比) 将会显著降低消费者的生长速 率。实验室模拟 (Urabe et al., 1997) 和原位试验 (Elser et al ., 2003) 研究都表明, 当喂以高 $\mathrm{C}: \mathrm{P}$ 比的 藻类时, 水蚤的生长受到 $\mathrm{P}$ 限制。Frost 和 Elser (2002) 通过控制蜉蝣 (Mayfly) 的食物及其 $\mathrm{C}: \mathrm{P}$ 比值 试验发现, 供应食物量不足会造成蜉蝣的生长速率 下降; 而在食物供应充足的情况下, 喂以低 $\mathrm{C}: \mathrm{P}$ 比 值的食物时蜉蝣生长更快, 并且蜉蝣的 $\mathrm{P}$ 含量与其 食物的 P 含量正相关。Sterner 和 George (2000) 研究 了海洋中鲤科中的几种鱼的 $\mathrm{C}: \mathrm{N}: \mathrm{P}$ 比值及其与食 物 (海藻) 的 $\mathrm{C}: \mathrm{N}: \mathrm{P}$ 比值之间的关系, 探讨了通过鱼 
驱动的食物链的养分循环状况, 结果发现, 鲤鱼的 $\mathrm{N}: \mathrm{P}$ 比值与它们的食物的 $\mathrm{N}: \mathrm{P}$ 比值相似; 不同湖泊 的鲤鱼养分含量变化很小, 尽管食物的养分含量变 化很大; $\mathrm{C}: \mathrm{N}: \mathrm{P}$ 比值稳定性的维持, 是由鲤鱼对养分 的平衡吸收而不是由鲤鱼对食物的消化速率决定 的。

生态化学计量学理论在陆地生态系统消费者驱 动的养分循环研究中的应用相对较少。GRH 理论 认为以含 $\mathrm{P}$ 量丰富的物质为食物的有机体具有更高 的 P 和 RNA 含量, 以及更快的生长速率。这种机制 暗示一种潜在的因果关系链, 即土壤有效 $\mathrm{P}$ 含量影 响植物生长和组织 $\mathrm{P}$ 含量, 然后进一步影响取食者 的 $\mathrm{P}$ 和核酸含量, 生长和繁殖以及种群动态。 Schade 等(2003)研究了一个沙地生态系统土壤中有 效 P 的时空分布对一种豆科灌木 ( Prosopis velutina) 和它的一种主要昆虫类取食者 (Sabinia setosa) 的化 学计量组成的影响。结果表明, 这种灌木叶片的 $\mathrm{C}$ : $\mathrm{P}$ 比值受到了土壤有效 $\mathrm{P}$ 时空分布变化的影响, 两 者呈负相关; 正如 GRH 理论预测, 取食者 P 和 RNA 含量能够反映土壤有效 $\mathrm{P}$ 和这种灌木叶片的 $\mathrm{C}: \mathrm{P}$ 比值, 而且这种取食者的种群数量也与植物叶片的 $\mathrm{C}: \mathrm{P}$ 比成反比。Elser 等 (2000a) 通过比较陆地植物 叶片的元素比值与昆虫取食的关系, 表明这些陆地 植物的平均 $\mathrm{C}: \mathrm{P}$ 和 $\mathrm{N}: \mathrm{P}$ 比都高于这些植物取食者 的相应比值, 这有可能是因为植物通过低的 $\mathrm{P}$ 含量 来限制取食者的种群发展。

近 10 年来, 生态化学计量学在消费者驱动的养 分循环研究中的应用逐渐增多, 研究范围逐渐拓宽。 比如, 食物化学计量比值影响动物进化的研究开始 大量出现 (Elser et al., 1996, 2000b; Markow et al., 1999); 利用生态化学计量学对水生和陆地生态系统 微生物食物网的研究也大量出现,一些已开展的研 究表明元素的化学计量关系可以调节养分的净矿化 和固持量 ( Tezuka, 1989; Chrzanowski et al., 1996; Paul \& Clark, 1996) 及鞭毛虫-细菌间的相互作用 (Caron et al., 1990)。

\section{2 限制性元素的判断}

养分的可利用性/供应量能够影响许多陆地、水 生和海洋生态系统的生产力、生物组成、生物多样 性、物种动态, 以及植物、动物和微生物种群间的交 互作用 (Vitousek, 2004), 养分的供应量是否充足是 影响有机体生长、种群结构、物种相互作用和生态系 统稳定性的重要因素, 因此, 对这种供应量不足的养 分类型的判断就成为维护这个系统稳定的前提。生
态化学计量学涉及到消费者和它们的食物的元素比 率 $(\mathrm{C}: \mathrm{N} 、 \mathrm{C}: \mathrm{P}$ 和 $\mathrm{N}: \mathrm{P}$ 比), 并且认为相对需求量来说 供应量最少的元素就是“限制性”元素。同时, 生态 化学计量学理论认为有机体的元素组成比值是动态 稳定的, 有机体存在一个相对稳定的 C、N、P 元素比 值关系,而其中任何一种元素的巨大变化都将使这 一比值发生变化。因此, 通过 $\mathrm{C}: \mathrm{N}: \mathrm{P}$ 比值的变化, 该理论可以用来判断限制有机体生长、发育或繁殖 的元素类型。许多研究也表明生态计量比值能够有 效反映出限制性元素的种类 (Andersen \& Hessen, 1991; Koerselman \& Meuleman, 1996; Güsewell, 2004; Ågren, 2004）。有机物、食物网和生态系统中储存的 C 在一定程度上是由质量守恒原理和其它关键养分 元素(如 $N 、 P$ 等)的可获得量控制的。养分限制意 味着 $\mathrm{C}$ 的相对过量 (如, $\mathrm{C}: \mathrm{N} 、 \mathrm{C}: \mathrm{P}$ 上升), 同时, 也意 味着自养和异养生物的 $\mathrm{C}$ 汇可能不同。总体上, C 与养分比值通常较高且变化灵活的自养生物和分解 者, 与具有较低 $\mathrm{C}$ 与养分比值和生态化学控制较严 (变化幅度小) 的消费者的 $\mathrm{C}: \mathrm{N}: \mathrm{P}$ 比值差异较大。 因此, 食物网中的 $\mathrm{C}$ 利用效率可能主要由自养生物 的养分元素控制, 当食物 (自养生物) 中的 C 与养分 比值达到那些消费者的 $\mathrm{C}$ 与养分比值时, $\mathrm{C}$ 利用效 率将会增加（Hessen et al., 2004）。

化学计量比值的变化能够改变植食动物之间的 养分竞争, 从而改变自养生物养分限制的种类。在 研究海洋和湖泊等水域生态系统过程中, 对于海洋 水域中限制性元素种类的判断经历了很长的争论。 早期, 海洋生态学家 (如, Boynton et al., 1982; Smith, 1984)认为海洋中 $\mathrm{N}$ 是主要的限制性元素, 因 此, 他们主要是定量研究浮游动物的 $\mathrm{N}$ 循环过程; 而另一些生态学家认为, 由于海洋可以通过对大气 $\mathrm{N}_{2}$ 的固定来保证 $\mathrm{N}$ 的供应, 因此, $\mathrm{P}$ 是海洋中最短 缺的元素 (Meybeck, 1982)。这一时期, 海洋生态学 家除了考虑浮游动物对海洋初级生产力的影响, 几 乎没有考虑过浮游动物造成的 $\mathrm{N}$ 和 $\mathrm{P}$ 养分的再生 以及这种再生的重要意义( Downing, 1997)。

但是, 20 世纪 80 年代, Lehman(1984) 的研究指 出, 浮游动物并不是以同样的效率循环利用 $\mathrm{N}$ 和 $\mathrm{P}$, 这可能造成浮游动物通过改变海洋生态系统的 $\mathrm{N}: \mathrm{P}$ 比值供应而影响浮游植物群落。Elser 等(1988)研究 发现, 由于鱼类取食产生变化, 浮游动物群落的组成 从水蚤 (Daphnia) 占优势转变为桡足类动物 (Calanoid copepod) 占优势, 这个过程同时伴随着限 制浮游植物生长的养分元素类型的变化。在水虫占 
优势的情况下, 浮游植物的生长受到 P 的限制, 而在 桡足类动物占优势的情况下浮游植物的生长就会受 到 N 的限制。Andersen 和 Hessen (1991) 的研究表 明, 与水蚤相比, 桡足类动物能够稍微提高 $\mathrm{N}$ 含量, 但却能够大量降低 P 含量。因此, 水虫具有较低的 $\mathrm{N}: \mathrm{P}$ 比值 (约为 $14: 1$ ), 而大多数桡足类动物的 $\mathrm{N}: \mathrm{P}$ 比值较高 (约为 $30 \sim 50: 1$ )。 Sterner 等 (1992) 总结 Elser 等 (1988) 的报道认为, 这是消费者驱动的化学 计量改变的结果。水虫占优势的浮游动物的聚集不 同程度地造成动物生物量中积累了大量的 $\mathrm{P}$, 而 $\mathrm{N}$ 却以一种相对较高的速率进行循环, 因此, 使浮游植 物的生长朝着 $\mathrm{P}$ 限制的方向发展。当由桡脚类动物 占优势造成的浮游动物聚集时, 浮游动物群落积累 大量 $\mathrm{N}$, 而 $\mathrm{P}$ 的循环利用速率很快, 从而导致浮游植 物的生长受到 $\mathrm{N}$ 的限制。

在陆地生态系统中, 土壤细菌的 $\mathrm{C}: \mathrm{N}$ 比值一般 为 6 , 而植物组织和调落物的 $\mathrm{C}: \mathrm{N}$ 比值通常大于 100。因此, Vitousek 等(2002)认为, 在陆地生态系统 中, 相对于它们的需求量, 动物和微生物都是生存于 一个 $\mathrm{C}$ 含量丰富而 $\mathrm{N}$ 不足的世界中。动物的营养 和生长经常受它们的食物 $\mathrm{N}$ 含量的限制, 造成动物 体内蛋白质含量不足 (White, 1993)。微生物在分解 过程中也会受到调落物中 $\mathrm{N}$ 含量的影响, 为了自身 的繁殖和生长, 微生物会保留大部分从分解基质中 获得的 $\mathrm{N}$, 并且也直接从土壤中吸收无机 $\mathrm{N}$ 加以补 充, $\mathrm{N}$ 从有机物转化到生物可利用状态的过程落后 于植物调落物的分解过程, 因此, 植物往往容易受到 $\mathrm{N}$ 不足的限制。生物固 $\mathrm{N}$ 是一个非常耗能的过程, 需要消耗大量的 $\operatorname{ATP}($ 含 P)。许多研究也表明, 在 陆地和海洋生态系统中, 藻青菌类 (Cyanobacterial systems) 微生物受到 P 的供应不足的限制, 从而抑制 N 的固定 (Smith, 1993a; Crews, 1993a, 1993b)。最 近一项研究也发现, 在长期缺乏灾难性干扰的情况 下, 森林生态系统原始演替或次生演替的后期阶段, 常常伴随着生产力的下降以及腐殖质和新鲜调落物 中 $\mathrm{N}: \mathrm{P}$ 比的增加, 表明随着时间推移森林生态系统 越来越受到 P 的限制(Wardle et al., 2004)。

植物组织 $\mathrm{C}: \mathrm{N}: \mathrm{P}$ 化学计量比值的变化可能是 由于植物能够储存超过它们需要的能量和养分量, 从而灵活地调整它们的生长速率以适应周围的环境 (Marschner, 1995)。元素限制作用能够改变植物的 化学组成, 这些限制作用也能够导致随着植物生长 速率的增加, $\mathrm{N}: \mathrm{C}$ 和 $\mathrm{P}: \mathrm{C}$ 比增加, 而 $\mathrm{N}: \mathrm{P}$ 比降低 (Ågren, 2004)。这是因为高的生长速率需要更多的
rRNA 投入以生产生长所需的蛋白质, 而 rRNA 是植 物的一个主要 $\mathrm{P}$ 库, 因此, rRNA 含量的增加将导致 植物细胞中 $\mathrm{P}$ 浓度的不成比例增加, 从而降低 $\mathrm{N}: \mathrm{P}$ 比。

植物叶片的 $\mathrm{N}: \mathrm{P}$ 临界比值被认为可以作为判 断环境对植物生长的养分供应状况的指标 (Wassen et al., 1995; Aerts \& Chapin, 2000; Güsewell, 2004)。 Sakamoto (1966) 发现当海藻 N:P 比值在 $10 \sim 17$ 范围 内时, $\mathrm{N}$ 和 $\mathrm{P}$ 对叶绿素的生产量的作用几乎相同 ( N、P 同时限制或都不限制生产量), 当 $N: P$ 比小于 10 时叶绿素的生产量仅受 $N$ 的限制, 而当 $\mathrm{N}: \mathrm{P}$ 比值 大于 17 时, 叶绿素的产生量只受 P 的限制。Wassen 等(1995)、Koerselman 和 Meuleman(1996)通过对湿地 植被施肥试验表明, $\mathrm{N}: \mathrm{P}$ 比大于 16 时, 可以认为这 个系统是受 $\mathrm{P}$ 限制的; 而当 $\mathrm{N}: \mathrm{P}$ 比小于 14 时, 这一 生态系统被认为是受 $N$ 限制的。在 $N: P$ 比为 14 16 范围内, 被认为是受到 2 种元素共同限制或 2 种 元素都不缺少。Braakhekke 和 Hooftman (1999) 通过 对土壤养分贫㾉的草地进行施肥试验, 认为植物叶 片 $\mathrm{N}$ 或 $\mathrm{P}$ 不足的 $\mathrm{N}: \mathrm{P}$ 比临界值分别为 10 和 14 。结 合叶片中 $\mathrm{N}$ 和 $\mathrm{P}$ 含量大小, Braakhekke 和 Hooftman (1999)认为 $\mathrm{N}: \mathrm{P}$ 比大于 14 而植物叶片 $\mathrm{P}$ 含量低于 $1.0 \mathrm{mg} \cdot \mathrm{g}^{-1}$ 时, 这个系统是受 $\mathrm{P}$ 限制的; 而当 $\mathrm{N}: \mathrm{P}$ 比 小于 10 和植物叶片 $\mathrm{N}$ 含量低于 $20.0 \mathrm{mg} \cdot \mathrm{g}^{-1}$ 时, 这 一生态系统被认为是受 $\mathrm{N}$ 限制的。 $\mathrm{N}: \mathrm{P}$ 比在 $10 \sim$ 14 范围内的被认为是受到 2 种元素共同限制(当 $\mathrm{P}$ $<1.0 \mathrm{mg} \cdot \mathrm{g}^{-1}$ 和 $\mathrm{N}<20.0 \mathrm{mg} \cdot \mathrm{g}^{-1}$ 时)或两种元素 都不缺少 (当 $\mathrm{P}>1.0 \mathrm{mg} \cdot \mathrm{g}^{-1}$ 和 $\mathrm{N}>20.0 \mathrm{mg} \cdot \mathrm{g}^{-1}$ 时)。当然, 由于研究区域、植物器官及植物种类 (种 间和种内) 的差异, $\mathrm{N}: \mathrm{P}$ 临界指标也会发生很大变化 (Güsewell, 2004)。

目前, 国内也有研究者注意到 $\mathrm{N}: \mathrm{P}$ 化学计量比 在判断植物生长的元素限制性中的应用 (Chen et al., 2004; Zhang et al., 2004)。张明霞等(2004)根 据施肥试验结果验证了 $\mathrm{N}: \mathrm{P}$ 比值是相对稳定性的, 可以作为判断生境中 $\mathrm{N}$ 或 $\mathrm{P}$ 不足的指标, 并且根据 施肥试验获得了内蒙古草原区草本植物的 $\mathrm{N}: \mathrm{P}$ 比 临界指标, 他们的研究结果初步认为 $\mathrm{N}: \mathrm{P}$ 比小于 21 , 则这种物种受 $N$ 限制, 而当 $N: P$ 比大于 23 时, 则 受 P 限制。

\section{3 全球 $\mathrm{C} 、 \mathrm{~N} 、 \mathrm{P}$ 生物地球化学循环}

元素在全球生物地球化学循环中并不是单个进 行的, 元素之间存在相互作用。在所有元素中, C 代 表了地球上所有生命形式的通用媒介, 许多元素之 
间的交互作用都是通过 $\mathrm{C}$ 与其它养分的比值关系 来进行调节的 (Melillo et al., 2003)。因此,生物的 $\mathrm{C}: \mathrm{N}: \mathrm{P}$ 化学计量比对全球 $\mathrm{C}$ 和养分循环具有重要 影响, 生物量中 $\mathrm{C}$ 与养分比值的差异能够调控生态 系统中有机物质的去处, 影响生物圈中 $\mathrm{C}$ 的消耗或 固定过程。目前, 人类活动对生物地球化学循环的 影响逐渐加剧, 而人类活动对全球 $\mathrm{C}$ 循环的影响与 自然界本身的 C 循环过程完全不同, 因此, 必须了 解生物群落中 C、P、N 的耦合关系, 以更好地预测人 类干扰对区域生态系统和生物圈的影响 (Sterner \& Elser, 2002)。

目前, 全球环境和气候变化对 $\mathrm{N}$ 和 $\mathrm{P}$ 在生物地 球化学 $\mathrm{C}$ 循环中的控制性作用的关系存在两个问 题: 1) 陆地上有多少新的初级生产量可以归功于土 壤有机物质的分解和化肥的施用? 2)海洋中有多少 新的初级生产量是由陆地运输到海洋的养分和由深 海运输到海洋表层而产生的? 通过 $\mathrm{C}: \mathrm{N}: \mathrm{P}$ 化学计 量关系的确立, 生态化学计量学为这些问题的回答 提供了契机 (Lerman et al., 2000)。

海洋的生产量占整个生物圈生产量的 $50 \%$ 左 右, 它是大量有机物质长期储存的地方, 因此, 在很 大程度上海洋能够影响全球气候。“生物葲”( Biological pump) 指的是海洋中 $\mathrm{C}$ 从表层向深层净移动 的过程, 这个过程能够导致表层水域生产者对 $\mathrm{CO}_{2}$ 的同化和表层生产者固定的 $\mathrm{C}$ 往温跃层以下运输 (Lalli \& Parsons, 1997), 结果促进了海洋对 $\mathrm{CO}_{2}$ 的吸 收, 使 C 深埋于海洋底层沉积物中。元素化学计量 比从两个方面影响生物泵功能的发挥 (Falkowski et $a l$. , 2000), 一个是上层海水中溶解养分 $(\mathrm{N}$ 和 $\mathrm{P}$ ) 的 利用效率; 另外一个就是初级生产中形成的有机物 质的 $\mathrm{C}: \mathrm{N}: \mathrm{P}$ 化学计量值, 只有在表层生产的物质 $\mathrm{C}$ 与养分比值大于从中层进入表层的物质 $\mathrm{C}$ 与养分 比值情况下, 生物㫤才能使 C 净储存于深海 ( Karl, 1999）。整体上, 海洋中 $\mathrm{C}: \mathrm{N}: \mathrm{P}$ 比值是比较平衡的 (约等于 Redfield 比值)。但是, 由于世界海洋面积 约占整个地球的 $70 \%$, 如果海洋中的 $\mathrm{C}: \mathrm{N}: \mathrm{P}$ 比值发 生哪怕一个微小的变化都可能会影响全球的碳循 环。海洋中的可溶性有机质 (Dissolved organic matter) 是生物圈中最大的碳库之一, Hopkinson 和 Vallino(2005)通过总结近 10 年来的世界几大海洋的研 究, 发现海洋中的可溶性有机质是以一种 $\mathrm{C}: \mathrm{N}: \mathrm{P}=$ 199:20:1 的比值进行矿化的, 这个比值显著高于 Redfield 比值 $(106: 16: 1$ ), 整个海洋的 $\mathrm{C}: \mathrm{N}$ 和 $\mathrm{C}: \mathrm{P}$ 比 值表现为一种 $\mathrm{C}$ 丰富的状态, 即 $\mathrm{C}$ 分别比 Redfield
比值高出 $62 \%$ 和 $87 \%$ 。因此, 如果进入到了海洋表 层水体中的 $\mathrm{N}$ 和 $\mathrm{P}$ 增加, 那么就将有更多的可溶性 有机碳进入海洋中。对厄尔尼诺引起的南方涛动 (ENSO) 研究表明, 在 ENSO 期间, 海水增暖造成海洋 表层混合层变窄和垂直的养分供应量减少, 海洋生 物量的 $\mathrm{C}$ 与养分比值增加, 可能原因是混合层的窄 化使得表层水域光/养分比值增加, 从而减缓了表层 的光限制, 加剧了养分的限制 (Karl, 1999)。

人类活动正在史无前例地改变全球生物地球化 学循环 (Falkowski et al., 2000), 这些改变大部分是 与人类的食物生产、城市化、工业化和对水分过度利 用等活动有关。陆地与水域生物地球化学循环的改 变并不是单个元素循环的变化, 而是多种元素共同 变化的, 自然界元素间的相互关系也受到人类活动 的改变(Melillo et al., 2003)。而自然界本身的 C、 $\mathrm{N} 、 \mathrm{P}$ 生物地球化学循环的耦合作用已经很复杂, 因 此, 如何定量评价人类的影响?人类改变后的全球 $\mathrm{C}: \mathrm{N}: \mathrm{P}$ 计量比值是多少? 应用生态化学计量学理论 能够部分回答这些问题。人类对全球 C、N、P 的影 响主要通过生物量生产(主要通过农业)和能量消耗 两个方面, 人类活动, 诸如化石燃料燃烧、土地利用 变化和工业化等造成了大量 $\mathrm{CO}_{2}$ 释放 (Hoffert et al., 1998; Austin et al., 2003); 化肥的生产、化石燃 料的燃烧和固氮作物的推广所造成的 $\mathrm{N}$ 输入远大 于自然系统对 $\mathrm{N}$ 的固定量 (Galloway \& Cowling, 2002); 而矿石的开采、化肥的施用以及工业上 P 的 生产所造成的 $\mathrm{P}$ 输入也远超过自然界中由岩石风化 产生的 P(Bennett et al., 2001)。Falkowski 等(2000) 研究发现, 人类活动使 $\mathrm{C} 、 \mathrm{~N} 、 \mathrm{P}$ 通量分别增加了 $13 \% 、 108 \%$ 和 400\%, 自然过程的全球 $\mathrm{C}: \mathrm{N}: \mathrm{P}$ 计量 比约为 $20333: 43: 1$, 人类活动造成的 $\mathrm{C}: \mathrm{N}: \mathrm{P}$ 计量比 约为 $667: 12: 1$ (表 1)。从 $\mathrm{C}: \mathrm{N}: \mathrm{P}$ 计量比的对比可以 看出, 人类对 $\mathrm{N}$ 和 $\mathrm{P}$ 循环的影响强于对 $\mathrm{C}$ 循环的影 响, 与 $\mathrm{C}$ 相比人类对全球生态系统的影响主要是增 加了 $\mathrm{N}$ 和 $\mathrm{P}$ 。由于人类的这种大规模的“富营养化” 活动, 整体上, 地球上的总体生物群的养分利用效率 (单位养分的生物量生产能力) 可能出现了下降。

在陆地生态系统 C、N、P 循环研究中, McGroddy 等(2004)通过总结世界范围内森林生态系统的研究 结果发现, 不同的生物群(温带阔叶林、温带针叶林 和热带森林) 具有不同的 $\mathrm{C}: \mathrm{N}: \mathrm{P}$ 比值, 而对于整个 全球森林生态系统来说, 树木叶片的 C、N、P 原子比 率为 $1212: 28: 1$, 森林调落物的 $\mathrm{C} 、 \mathrm{~N} 、 \mathrm{P}$ 原子比率为 $3007: 45: 1$ 。树木叶片和调落物的 $\mathrm{C}: \mathrm{N}: \mathrm{P}$ 比值表 
表 1 人类活动对 $\mathrm{C} 、 \mathrm{~N} 、 \mathrm{P}$ 全球生物地球化学循环的影响 (Falkowski et al., 2000)

Table 1 Examples of human intervention in global biogeochemical cycles of C, N, P (Falkowski et al., 2000)

\begin{tabular}{|c|c|c|c|c|}
\hline \multirow{2}{*}{$\begin{array}{c}\text { 元素 } \\
\text { Element }\end{array}$} & \multirow{2}{*}{$\begin{array}{l}\text { 产生来源 } \\
\text { Sources of flux }\end{array}$} & \multicolumn{2}{|c|}{$\begin{array}{c}\text { 产生大小 } \\
\text { Magnitude of flux }\left(10^{9} \mathrm{~kg} \cdot \mathrm{a}^{-1}\right)\end{array}$} & \multirow{2}{*}{$\begin{array}{l}\text { 人类的影响 } \\
\text { The change due to } \\
\text { human activities }(\%)\end{array}$} \\
\hline & & $\begin{array}{l}\text { 自然 } \\
\text { Natural }\end{array}$ & $\begin{array}{l}\text { 人类 } \\
\text { Anthropogenic }\end{array}$ & \\
\hline \multirow[t]{2}{*}{ C } & $\begin{array}{l}\text { 陆地生物呼吸和分解 Terrestrial respiration and } \\
\text { decay } \mathrm{CO}_{2}\end{array}$ & 61000 & 8000 & +13 \\
\hline & $\begin{array}{l}\text { 化石燃料燃烧和土地利用改变 Fossil fuel and } \\
\text { land use } \mathrm{CO}_{2}\end{array}$ & & & \\
\hline \multirow[t]{2}{*}{$\mathrm{N}$} & 自然界生物固氮 Natural biological fixation & 130 & 140 & +108 \\
\hline & $\begin{array}{l}\text { 农作物、化石燃料燃烧和施肥 Fixation owing to } \\
\text { rice cultivation, combustion of fossil fuels, and pro- } \\
\text { duction of fertilizer }\end{array}$ & & & \\
\hline \multirow[t]{2}{*}{$\mathrm{P}$} & 风化 Chemical weathering & 3 & 12 & +400 \\
\hline & 采矿 Mining & & & \\
\hline
\end{tabular}

明, 陆地生态系统植被的 $\mathrm{C}$ 含量相对于 $\mathrm{N}$ 和 $\mathrm{P}$ 要高 于淡水自养生物 (淡水生态系统自养生物的 $\mathrm{C}: \mathrm{N}: \mathrm{P}$ 比值约为 306:30:1 (Elser et al ., 2000a)), 但两类生 态系统的 N:P 比值相似。Ågren (2004) 对一种水生 植物和一种陆生植物的 $\mathrm{N}: \mathrm{P}$ 比值进行比较后, 也发 现水生植物和陆生植物的 $\mathrm{N}: \mathrm{P}$ 比值基本相似, 而两 者之间的微小差异可能主要来源于水生植物比陆生 植物具有更大的最大相对生长速率, 而且前者对养 分的奢侈吸收能力更强。这些研究表明, 两类生态 系统中自养生物光合器官的 $\mathrm{N}: \mathrm{P}$ 比值可能都受到 相似生理过程的控制。Jackson 等(1997)的研究也发 现, 全球植被细根的 $\mathrm{C}: \mathrm{N}: \mathrm{P}$ 比值为 $1158: 24: 1$, 与树 木叶片的 $\mathrm{C}: \mathrm{N}: \mathrm{P}$ 比值相近。调落叶片的 $\mathrm{C}$ 与养分 比值大于叶片的 C 与养分比值, 表明全球尺度上养 分再吸收 (特别是对 $\mathrm{P}$ 的再吸收) 是陆地森林植被的 一个重要机制。Vitousek (2003) 通过对夏威夷不同 土壤发育阶段森林生态系统主要组成树种的不同组 织 C: N、N : P 比值的研究发现, 桃金娘 (Metrosideros polymorpha) 花、叶片、叶片调落物、根系和木质部分 的 $\mathrm{C}: \mathrm{N}$ 比值在不同生态系统中差异很大, 而 $\mathrm{N}: \mathrm{P}$ 比 值基本相似; 各发育阶段的不同树种对应组织的 $\mathrm{C}$ : $\mathrm{N}$ 比值差异也很大, 而 $\mathrm{N}: \mathrm{P}$ 比值也基本相似, 表现 出 $\mathrm{N}: \mathrm{P}$ 比值比较恒定, 而 $\mathrm{C}: \mathrm{N}$ 比值变化较大。 $\mathrm{Vi}-$ $\operatorname{tousek}(2003$ )认为化学计量的 (Stoichiometric) 和弹性 的 (Flexible)生态交互作用共同控制着生物对元素的 需求和供应, 而这两种作用的共存也是导致陆地生 态系统复杂性的因素之一。McGroddy 等(2004)和 Vitousek(2003)等的工作已经为陆地生态系统的研 究提供了一定的基础, 但是, 陆地生态系统的复杂性
决定了目前的研究还远远不够, 有待于进一步加强。

\section{5 结 论}

化学元素是生物体最本质的组成成分, 它能够 对有机体的许多行为进行有序调控, 生态化学计量 学理论被认为在所有生物系统和全球生物地球化学 循环研究中具有重要价值 (Michaels, 2003), 但是, 生 态化学计量学并不是万能的, 它至少在目前还不能 回答太多生物学问题。由于受到研究区域集中 (海 洋生物、微生物相对较多)、研究物种数少 (检验理论 的物种数目有限) 和理论提出时间短等限制, 以及部 分研究者对一些物种的研究未能验证生态化学计量 学理论, 关于生态化学计量学的研究还远远不够, 生 态化学计量学理论是否适用于全部生物还有待于进 一步检验。目前, 生态化学计量学是生态学研究的 一个热点, 发展前景十分诱人。今后这方面的研究 将可能主要集中于以下几个方面:

1)陆地生态系统生态化学计量

生态化学计量学理论的提出、理论的验证和丰 富大都是基于对海洋生物的研究获得的, 而对于陆 地生物的研究相对很少, 这可能是因为陆地生态系 统生物地球化学循环的周转速率很慢, 而且, 陆地生 态系统中富含各种难以分解的含 $\mathrm{C}$ 化学物质, 以及 影响 $\mathrm{C}: \mathrm{N}: \mathrm{P}$ 计量比值的因素更多, 这就使陆地生态 系统比海洋生态系统更为复杂。因此, 这一理论还 需要在对陆地生物进行广泛研究的基础上得以最终 验证和确立。

\section{2)养分胁迫下生物生长发育的适应机制}

生物对养分胁迫的响应一直是生态学研究的热 
点问题之一, 胁迫响应机制的探讨从分子、细胞、生 理生态再到种群动态层次都有, 但问题似乎仍未解 决, 生态化学计量学理论的应用有望在这一问题上 获得更多确定的答案。

\section{3)利用生态化学计量学理论解释生命现象}

生态化学计量学理论认为, 生物的生命形式可 以简化成简单的元素比值, 因此, 这一简化有可能促 进对生物起源、进化、生命维持以及生态系统水平养 分供应与需求平衡机制的探索。

\section{4) 全球 C、N、P 循环}

$\mathrm{CO}_{2}$ 是重要的温室气体, $\mathrm{C}$ 循环是生态学领域 的一个热点问题, 全球 $\mathrm{C}$ “失汇”及全球 $\mathrm{C}$ 循环的稳 定性如何维持仍然困扰着生态学家, 而生态化学计 量学的提出可以阐明海洋和陆地植被对 $\mathrm{C}$ 的吸收 及释放机制。这种释放与吸收机制一旦研究清楚, 将有利于人类了解甚至是控制全球 $\mathrm{C}$ 循环。目前 已经有少部分研究表明了生态化学计量学理论在全 球 C 循环研究中的重要作用, 因此,这方面的研究 有待于进一步拓展。同样, 与 $\mathrm{C}$ 循环关系密切的 $\mathrm{N}$ 、 $\mathrm{P}$ 循环也将是今后研究的重点。在全球生物地球化 学研究中有许多急需解决的问题需要利用生态化学 计量学理论去解决。可以预期, 生态化学计量学将 继续得到更蓬勃的发展。

\section{参 考 文 献}

Aerts R, Chapin FS III (2000). The mineral nutrition of wild plants revisited: a re-evaluation of processes and patterns. Advances in Ecological Research, 30, $1-67$.

Agren GI (2004). The C: N : P stoichiometry of autotrophs-theory and observations. Ecology Letters, 7, 185 - 191 .

Allen TFH, Hoekstra TW (1992). Toward a Unified Ecology. Columbia University Press, New York.

Andersen T (1997). Pelagic Nutrient Cycles: Herbivores as Sources and Sinks. Springer-Verlag, Berlin.

Andersen T, Elser JJ, Hessen DO (2004) . Stoichiometry and population dynamics. Ecology Letters, 7, 884-900.

Andersen T, Hessen DO (1991) . Carbon, nitrogen, and phosphorus content of freshwater zooplankton. Limnology and Oceanography, 36, $807-814$.

Austin AT, Howarth RW, Baron JS, Chapin FS III, Christensen TR, Holland EA, Ivanov MV, Lein AY, Martinelli LA, Melillo JM, Shang C (2003). Human disruption of element interactions: drivers, consequences, and trends for the twenty-first century. In: Melillo JM, Field CB, Moldan B eds. Interactions of the Major Biogeochemical Cycles: Global Change and Human Impacts. Island Press, Washington, D.C., 15-45.

Belovsky GE (1978). Diet optimization in a generalist herbivore: the moose. Theoretical Population Biology, 14, $105-134$.

Bennett EM, Carpenter SR, Caraco NF (2001) . Human impact on erodable phosphorus and eutrophication: a global perspective.
BioScience, 51, $227-234$.

Boynton WR, Kemp WM, Keefe CW (1982) . A comparative analysis of nutrients and other factors influencing estuarine phytoplankton production. In: Kennedy VS ed. Estuarine Comparisons. Academic Press, New York, 69-70.

Braakhekke WG, Hooftman DAP (1999). The resource balance hypothesis of plant species diversity in grassland. Journal of Vegetation Science, 10, $187-200$.

Caron AC, Porter KG, Sanders RW (1990). Carbon, nitrogen and phosphorus budgets for the mixotrophic phytoflagellate Poterioochromonas malhamensis (Chrysophyceae) during bacterial ingestion. Limnology and Oceanography, 35, 433-443.

Chen GS, Zeng DH, Chen FS (2004). Foliar and surface soil nutrient concentrations of Pinus spp. plantations in relation to species and stand age in Zhanggutai sandy land, northeast China. Journal of Forestry Research, 15, 11 - 18 .

Chrzanowski TH, Kyle M, Elser JJ, Sterner RW (1996) . Element ratios and growth dynamics of bacteria in an oligotrophic Canadian shield lake. Aquatic Microbial Ecology, 11, 119 - 125.

Crews TE (1993a). Nutrient limitation to nitrogen fixation in young volcanic sites. Ecosystems, 2, 505-510.

Crews TE (1993b). Phosphorus regulation of nitrogen fixation in a traditional Mexican agroecosystem. Biogeochemistry, 21, 141 166.

Downing JA ( 1997 ). Marine nitrogen: phosphorus stoichiometry and the global N:P cycle. Biogeochemistry, 37, $237-252$.

Elser JJ, Acharya K, Kyle M, Cotner J, Makino W, Markow T, Watts T, Hobbie S, Fagan W, Schade J, Hood J, Sterner RW (2003). Growth rate-stoichiometry couplings in diverse biota. Ecology Letters, 6, 936 - 943.

Elser JJ, Dobberfuhl D, MacKay NA, Schampel JH (1996). Organism size, life history, and N:P stoichiometry: towards a unified view of cellular and ecosystem processes. BioScience, 46, $674-684$.

Elser JJ, Elser MM, MacKay NA, Carpenter SR (1988). Zooplankton-mediated transitions between $\mathrm{N}$ and $\mathrm{P}$ limited algal growth. Limnology and Oceanography, 33, 1-14.

Elser JJ, Fagan W, Denno RF, Dobberfuhl DR, Folarin A, Huberty A, Interlandi S, Kilham SS, McCauley E, Schulz KL, Siemann EH, Sterner RW (2000a). Nutritional constraints in terrestrial and freshwater food webs. Nature, 408, 578-580.

Elser JJ, Sterner RW, Gorokhova E, Fagan WF, Markow TA, Cotner JB, Harrison JF, Hobbie SE, Odell GM, Weider LW (2000b) . Biological stoichiometry from genes to ecosystems. $E$ cology Letters, 3, 540 - 550 .

Elser JJ, Urabe J (1999). The stoichiometry of consumer-driven nutrient recycling: theory, observations, and consequences. $E$ cology, 80, $735-751$.

Falkowski P, Scholes RJ, Boyle E, Canadell J, Canfield D, Elser J, Gruber N, Hibbard K, Högberg P, Linder S, Mackenzie FT, Moore B III, Pedersen T, Rosenthal Y, Seitzinger S, Smetacek V, Steffen W (2000). The global carbon cycle: a test of our knowledge of Earth as a system. Science, 290, $291-296$.

Frost PC, Elser JJ (2002). Growth responses of littoral mayflies to the phosphorus content of their food. Ecology Letters, 5, 232 240 .

Galloway JN, Cowling EB (2002). Reactive nitrogen and the 
world: 200 years of change. Ambio, 31, 64-71.

Gorokhova E, Kyle M (2002). Analysis of nucleic acids in Daphnia : development of methods and ontogenetic variations in RNADNA content. Journal of Plankton Research, 24, $511-522$.

Güsewell S (2004). N:P ratios in terrestrial plants: variation and functional significance. New Phytologist, 164, 243- 266.

Harris G (2003). Book review: ecological stoichiometry: biology of elements from molecules to the biosphere. Journal of Plankton Research, 25, 1183.

Hessen DO (1990). Carbon, nitrogen and phosphorus status in Daphnia at varying food conditions. Journal of Plankton Research, 12, $1239-1249$.

Hessen DO (1997). Stoichiometry in food webs-Lotka revisited. Oikos, 79, $195-200$.

Hessen DO, Ågren GI, Anderson TR, Elser JJ, de Ruiter PC (2004). Carbon sequestration in ecosystems: the role of stoichiometry. Ecology, 85, 1179 - 1192 .

Hoffert MI, Caldeira K, Jain AK, Haites EF, Harvey LDD, Potter SD, Schlesinger ME, Schneider SH, Watts RG, Wigley TML, Wuebbles DJ (1998). Energy implications of future stabilization of atmospheric $\mathrm{CO}_{2}$ content. Nature, 395, $881-884$.

Hopkinson CS, Vallino JJ (2005) . Efficient export of carbon to the deep ocean through dissolved organic matter. Nature, 433, 142 -145 .

Jackson RBH, Mooney HA, Schulze ED (1997) . A global budget for fine root biomass, surface area, and nutrient contents. Proceedings of the National Academy of Science of the United States of America, 94, 7362 - 7366 .

Jaenike J, Markow TA (2003) . Comparative elemental stoichiometry of ecologically diverse Drosophila. Functional Ecology, 17, $115-120$.

Karl DM (1999). A sea of change: biogeochemical variability in the North Pacific Subtropical Gyre. Ecosystems, 2, $181-214$.

Koerselman W, Meuleman AFM (1996). The vegetation N:P ratio: a new tool to detect the nature of nutrient limitation. Journal of Applied Ecology, 33, 1441 - 1450 .

Kooijman SALM (1995). The stoichiometry of animal energetics. Journal of Theoretical Biology, 177, $139-149$.

Lalli CM, Parsons TR (1997). Biological Oceanography: an Introduction 2nd edn. Butterworth-Heinemann, Oxford, UK.

Lehman JT (1984) . Grazing, nutrient release, and their impacts on the structure of phytoplankton communities. In: Meyers DG, Strickler JR eds. Trophic Dynamics Within Aquatic Ecosystems. Westview Press, Boulder, USA.

Lerman A, Mackenzie FT, Ver LMB (2000). Nitrogen and phosphorus controls of the carbon cycle. Journal of Conference Abstracts, 5, 638 .

Lindeman R (1942). The trophic dynamic aspect of ecology. Ecology, 23, 399-418.

Logan JD, Joern S, Wolesensky W (2004) . Control of CNP homeostasis in herbivore consumers through differential assimilation. Bulletin of Mathematical Biology, 66, $707-725$.

Lotka AJ (1925). Elements of Physical Biology. Williams and Wilkins, Baltimore.

Main TM, Dobberfuhl DR, Elser JJ (1997). N:P stoichiometry and ontogeny of crustacean zooplankton: a test of the growth rate hypothesis. Limnology and Oceanography, 42, $1474-1478$.
Makino W, Cotner JB (2004). Elemental stoichiometry of a heterotrophic bacterial community in a freshwater lake: implications for growth- and resource-dependent variations. Aquatic Microbial Ecology, 34, $33-41$.

Makino W, Cotner JB, Sterner RW, Else JJ (2003) . Are bacteria more like animals than plants? Growth rate and resource dependence of bacterial $\mathrm{C}: \mathrm{N}: \mathrm{P}$ stoichiometry. Functional Ecology, $17,121-130$.

Markow TA, Raphael B, Dobberfuhl D, Breitmeyer CM, Elser JJ, Pfeiler E (1999). Elemental stoichiometry of Drosophila and their hosts. Functional Ecology, 13, 78 - 84 .

Marschner H (1995) . Mineral Nutrition of Higher Plants. Academic Press, London.

McGroddy ME, Daufresne T, Hedin LO (2004). Scaling of C: N:P stoichiometry in forests worldwide: implications of terrestrial Redfield-type ratios. Ecology, 85, 2390-2401.

Melillo JM, Field CB, Moldan B (2003). Interactions of the Major Biogeochemical Cycles: Global Change and Human Impacts. Island Press, Washington, D.C.

Méndez M, Karlsson PS (2005). Nutrient stoichiometry in Pinguicula vulgaris: nutrient availability, plant size, and reproductive status. Ecology, 86, $982-991$.

Meybeck M (1982) . Carbon, nitrogen, and phosphorus transport by world rivers. American Journal of Science, 282, $401-450$.

Michaels AF (2003). The ratios of life. Science, 300, 906-907.

Paul EA, Clark FE (1996). Closing the nitrogen cycle: return of nitrogen to the soil. In: Paul EA, Clark FE eds. Soil Microbiology and Biochemistry. Academic Press, New York, 215- 243.

Redfield AC (1958). The biological control of chemical factors in the environment. American Scientist, 46, 205-211.

Redfield AC, Ketchum BH, Richards FA (1963). The influence of organisms on the composition of seawater. In: Hill MN ed. The Sea Vol. 2. Wiley Interscience, New York, 26- 797.

Reiners WA (1986). Complementary models for ecosystems. American Naturalist, 127, 59- 73 .

Sakamoto M (1966). Primary production by phytoplankton community in some Japanese lakes and its dependence on lake depth. Archiv fiur Hydrobiologie, 61, $1-28$.

Schade JD, Espeleta JF, Klausmeier CA, McGroddy ME, Thomas SA, Zhang L (2005) . A conceptual framework for ecosystem stoichiometry: balancing resource supply and demand. Oikos, 109, $40-51$.

Schade JD, Kyle M, Hobbie SE, Fagan WF, Elser JJ (2003). Stoichiometric tracking of soil nutrients by a desert insect herbivore. Ecology Letters, 6, 96-101.

Schimel DS (2003). All life is chemical. BioScience, 53, 521 524 .

Schindler DW (2003). Balancing planets and molecules. Nature, $423,225$.

Sherman F, Kuselman I (1999). Stoichiometry and chemical metrology: Karl Fisher reaction. Accreditation and Quality Assurance, 4, $230-234$.

Smith SV (1984) . Phosphorus versus nitrogen limitation in the marine environment. Limnology and Oceanography, 29, 1149 1160 .

Smith VH (1993a). Applicability of resource-ratio theory to microbial ecology. Limnology and Oceanography, 38, $239-249$. 
Smith VH (1993b). Implications of resource-ratio theory for microbial ecology. Advances in Microbial Ecology, 13, 1- 37 .

Stelzer RS, Lamberti GA (2002). Ecological stoichiometry in running waters: periphyton chemical composition and snail growth. Ecology, 83, 1039 - 1051 .

Sterner RW (1990). The ratio of nitrogen to phosphorus resupplied by herbivores: zooplankton and the algal competitive arena. American Naturalist, 136, 209-229.

Sterner RW, Clasen J, Lampert W, Weisse T (1998) . Carbon: phosphorus stoichiometry and food chain production. Ecology Letters, $1,146-150$.

Sterner RW, Elser JJ (2002) . Ecological Stoichiometry: the Biology of Elements From Molecules to Biosphere. Princeton University Press, Princeton.

Sterner RW, Elser JJ, Hessen DO (1992). Stoichiometric relationships among producers and consumers in food webs. Biogeochemistry, 17, 49-67.

Sterner RW, George NB (2000). Carbon, nitrogen, and phosphorus stoichiometry of cyprinid fishes. Ecology, 81, 127 - 140 .

Sterner RW, Hessen DO (1994). Algal nutrient limitation and the nutrition of aquatic herbivores. Annual Review of Ecology and Systematics, 25, $1-29$.

Tessier JT, Raynal DJ (2003) . Use of nitrogen to phosphorus ratios in plant tissue as an indicator of nutrient limitation and nitrogen saturation. Journal of Applied Ecology, 40, 523 - 534.

Tezuka Y (1989). The $\mathrm{C}: \mathrm{N}: \mathrm{P}$ ratios of phytoplankton determine the relative amounts of dissolved inorganic nitrogen and phosphorus released during aerobic decomposition. Hydrobiologia, 173, $55-62$.

Tilman D (1982). Resource Competition and Community Structure. Princeton University Press, Princeton.

Urabe J, Kyle M, Makino W, Yoshida T, Andersen T, Elser JJ (2002) . Reduced light increases herbivore production due to stoichiometric effects of light: nutrient balance. Ecology, 83, 619 -627 .

Urabe J, Nakanishi M, Kawabata K (1995) . Contribution of metazoan plankton to the cycling of $\mathrm{N}$ and $\mathrm{P}$ in Lake Biwa. Limnology and Oceanography, 40, 232-242.

Urabe J, Sterner RW (1996) . Regulation of herbivore growth by the balance of light and nutrients. Proceedings of the National Academy of Science of the United States of America, 93, 8465 -
8469.

Urabe JJ, Clasen J, Sterner RW (1997) . Phosphorus-limitation of Daphnia growth: is it real? Limnology and Oceanography, 42, 1436 - 1443.

Vanni MJ, Flecker AS, Hood JM, Headworth JL (2002). Stoichiometry of nutrient recycling by vertebrates in a tropical stream: linking biodiversity and ecosystem function. Ecology Letters, 5, $285-293$.

Vitousek PM (1982). Nutrient cycling and nutrient use efficiency. American Naturalist, 119, 553 - 572.

Vitousek PM (2003). Stoichiometry and flexibility in the Hawaiian model system. In: Melillo JM, Field CB, Moldan B eds. Interactions of the Major Biogeochemical Cycles: Global Change and Human Impacts. Island Press, Washington, D. C. , 117 - 133.

Vitousek PM (2004). Nutrient Cycling and Limitation: Hawai' $i$ as a Model System. Princeton University Press, Princeton.

Vitousek PM, Hättenschwiler S, Olander L, Allison S (2002) . Nitrogen and nature. Ambio, 31, 97-101.

Vogel S (1998). Academically correct biological science. American Scientist, 86, $504-506$.

Ward GM, Cummins KW (1979). Effects of food quality on growth of a stream detritivore, Paraendipes albimanus (Meigen) (Diptera: Chironomidae). Ecology, 60, 57-64.

Wardle DA, Walker LR, Bardgett RD (2004). Ecosystem properties and forest decline in contrasting long-term chronosequences. Science, 305, $509-513$

Wassen MJ, Olde Venterink HGM, de Swart EOAM (1995). Nutrient concentrations in mire vegetation as a measure of nutrient limitation in mire ecosystems. Journal of Vegetation Science, 6, 5 -16 .

White TCR (1993). The Inadequate Environment: Nitrogen and the Abundance of Animals. Springer-Verlag, Berlin.

Zhang LX (张丽霞), Bai YF (白永飞), Han XG (韩兴国) (2003) . Application of N:P stoichiometry to ecology studies. Acta Botanica Sinica (植物学报), 45, 1009 - 1018 .

Zhang LX (张丽霞), Bai YF (白永飞), Han XG (韩兴国) (2004) . Differential responses of N:P stoichiometry of Leymus chinensis and Carex korshinskyi to $\mathrm{N}$ additions in a steppe ecosystem in Nei Mongol. Acta Botanica Sinica (植物学报), 46, 259 -270 . 